\title{
Study on the Material Requisition System Based on Data Mining
}

\author{
Xuyun Hong \\ Business School, University of Shanghai for Science and Technology, Shanghai 200093, China \\ Tel: 86-21-5527-6487 E-mail: XUYUNH@usst.edu.cn \\ Liangwei Zhong (Corresponding author) \\ CAD Center, University of Shanghai for Science and Technology, Shanghai 200093, China \\ Tel: 86-21-5527-6487Ｅ-mail: zlv@usst.edu.cn \\ Jing Ni \\ Business School, University of Shanghai for Science and Technology, Shanghai 200093, China \\ Tel: 86-21-5527-1343 E-mail: nijing501@126.com
}

The research is financed by the Shanghai Leading Academic Discipline Project (No. S30504, J50503).

\begin{abstract}
The material requisition flow in the warehousing management was studied in the article, and combining the mining algorithm of causal rules, the material requisition based on data mining was developed. The system could fulfill the management requirements of the material requisition process for the enterprise, mine the data of material return and deeply analyze reasons, which can help the enterprise to enhance the production quality and reduce the production cost.
\end{abstract}

Keywords: Material requisition, Material return, Data mining, Causal rules

\section{Introduction}

The warehousing management information system has been used by many enterprises at present, and one important part in the system is the problems about how to require materials and distribute the material requisition for the manufacture enterprise. But the system can only simplify operators' operations to some extent, and it can not control the material requisition, and analyze the data of the material wastes.

To solve above problems, the material requisition system based on data mining is developed by J2EE. It can realize data sharing with PDM, avoid the data failure because of manual input, realize the material requisition control and data query and statistic analysis, and liberate operators from multifarious operation flows and large numerous of product information. The new system uses the data mining technology to analyze the data of material requisition and help decision-making, which can reduce the manufacturing cost.

\section{Function design}

The material consumption norm is the amount of various raw materials which must be consumed to make unit product (or part) according to many regulations such as product design structure, technical requirement, technical method and production technical condition under certain production, technology and organization conditions. It can standardize the management of the material distribution and use process, and it is the important system to realize the real-time control of the material cost. Its target is to strictly implement the material management system, strengthen saving, reduce waste, realize the real-time control of material cost in the workshop, strengthen the dynamic management of the material consumption norm, reduce the material consumption cost and enhance the economic benefits. Based on product design, production technology and arts, it can realize the cost control by systematic and refined management.

The material requisition is the process that the manufacturing department draws the materials from the warehouse according to BOM and implements manufacturing or assembling, so it uses the ODBC technology to link the material data in the PDM system and realize the real-time updating of data. 
Except for the basic material data, the type and quantity of requisition materials are the direct problem faced by the manufacture enterprises, so before the concrete contents of the material requisition are confirmed, the product type, material sort and material norm should be first confirmed. Generally, these contents are contained in the work order, and one work order can confirm the product name, the product chart No., product type and specs, sub-factory and product quantity. It comes from two departments. First, according to the yearly performance, the enterprise management department establishes the product manufacture plan of the next year, and the plan is turned into the work order according to the corresponding rules, and the work order is issued to the workshop, and these products are the pre-investing products, i.e. the standard type specs, and the production quantity of each product and each work order is a fixed value. Second, the work order comes from the sales department, if the products signed in the contract are non-pre-investing products (the product type and specs are non-standard), the non-pre-investing work order is generated, and the demand quantity is the production quantity, and the order is transferred to the workshop. If the sales quantity of the pre-investing product exceeds the planning quantity, so the new work order is generated. The storage personnel confirm the part material and material norm according to the work order, and fill in the material requisition according to the demand quantity of the workshop.

The requisition materials in the workshop are divided into the general requisition materials, odd lot (shortage) requisition materials and return materials. The material return is the operation that after the material requisition is filled in, the quality problem in the roughcast or disqualified manufacturing is found in the material requisition or production process, and the materials need to be returned. The reasons of material return include the material scrap and the working scrap. The material scarp occurs because of the problems existing in the raw materials, such as the material crack, and illegal roughcast size. The working scrap means the wasters induced in the manufacturing process, and except for the manufacture personnel are not familiar with the operation or perform incorrect manipulation, most working scarps come down to the quality of the product design and technological method. However, many records of material return are accumulated in the database, and they can not be utilized to embody their values, so much information is wasted. In addition, the increase of wasted materials will increase the material consumption, and enhance the production cost of the product, and reduce the profit of enterprise, so the occurrence of scrap should be reduced from the economic angle. The enterprise should effectively utilize the data of material return, deeply analyze and mine the biggest factor influencing the production in the workshop, discover the concrete reasons and possible problems to form the information for the decision-making, and accordingly standardize the material return and the material utilization, and reduce the manufacturing cost.

Figure 1 is the system functional diagram.

User management: the operations such as adding, freezing, deleting and modifying user information, and the setting of right.

Material requisition print: the material requisition is divided into the general material requisition, shortage, working scrap and material scrap, and the operations when the printer breaks down or jams papers. To simplify the operation, the check box is set up for users to select the appointed parts, and the users can also appoint printing one or multiple parts, and the operation is more convenient.

Data query: users can inquire the requisition record of certain part according to the requisition number, work order, production and part information, and inquire the requisition of various parts under appointed work order for the surplus of the corresponding work order.

Data analysis: according to the time input by the users, the system can calculate the happening probability of various reasons for each product, mine the main reason to induce the working scrap, and generate the important information to enhance the quality of product design and productivity, and save resources. The outputs of various statistical analysis values under this module include the product quantity, proportion, total happening probability of various reasons, and happening probability of various products, main influencing factor and heavy weight in the periodic production.

\section{Key technology}

The key technology of the system is the data analysis module, and one associated rule miner is developed, and it takes various reasons to induce the working scrap in the production as the analysis variables, discovers the concealed rules in large numerous material return data, finds out the concealed association in data, i.e. the association between variables and working scrap, so the information which can help the enterprise to make decision will be formed.

The mining of associated rules is one important part of data mining. If certain rule exists in two or multiple variables, it is called the association, and it can be divided into simple association, time association and causal association. The target of association analysis is to discover the interesting association or correlative relation in larger numerous information or information items. Sometimes, the associated function of data in the database is not known, even can not be confirmed, so the rules to generate the association analysis have certain creditability.

Supposed that $\mathrm{D}$ is the appointed database, and minsupp, minconf, $\gamma, \alpha, \lambda$ and $\eta$ are appointed threshold values and $\mathrm{M}_{\mathrm{Y} \mid \mathrm{X}}$ 
is the conditional probability matrix, so the mining algorithm of the associated rules in the data base $\mathrm{D}$ can be described as follows.

Algorithm1 Causality DB

Input: $\mathrm{D}$ : database, minsupp, minconf, $\alpha, \lambda, \eta$ : threshold values;

Output: $\mathrm{X} \rightarrow \mathrm{Y}$ : causal rule, $\mathrm{M}_{\mathrm{Y} \mid \mathrm{X}}$ : the conditional probability matrix of $\mathrm{Y}$ given $\mathrm{X}$;

(1) call procedure partitionData;

(2) for $\mathrm{X}, \mathrm{Y} \in \mathrm{OIV}$ do

for each element $a$ in $\mathrm{R}(\mathrm{X})$ and $\mathrm{b}$ in $\mathrm{R}(\mathrm{Y})$ do

let $p(Y=b \mid X=a)=p(Y=b \wedge X=a) / p(X=a)$;

let $\mathrm{CRSET} \leftarrow$ the rule $\mathrm{X} \rightarrow \mathrm{Y}$ as a candidate rule;

with conditional probability matrix of $Y$ given $\mathrm{X}: \mathrm{M}_{\mathrm{Y} \mid \mathrm{X}}$;

end for

end for

(3) for each extracted rule $\mathrm{R}$ with $\mathrm{M}_{\mathrm{Y} \mid \mathrm{X}}$ in CRSET do

let $\mathrm{S}_{\text {support }} \leftarrow\left\{\left(\mathrm{x}_{\mathrm{j}}, \mathrm{y}_{\mathrm{i}}\right) \mid \mathrm{p}\left(\mathrm{y}_{\mathrm{i}} \cup \mathrm{x}_{\mathrm{j}}\right) \geq \operatorname{minsupp} \wedge(1 \leq \mathrm{i} \leq \mathrm{m}) \wedge(1 \leq \mathrm{j} \leq \mathrm{n})\right\}$;

let $\mathrm{S}_{\text {conf }} \leftarrow\left\{\left(\mathrm{xj}, \mathrm{y}_{\mathrm{i}}\right) \mid \mathrm{p}\left(\mathrm{Y}=\mathrm{y}_{\mathrm{i}} \mid \mathrm{X}=\mathrm{x}_{\mathrm{j}}\right) \geq \operatorname{minconf} \wedge(1 \leq \mathrm{i} \leq \mathrm{m}) \wedge(1 \leq \mathrm{j} \leq \mathrm{n})\right\}$;

let $\mathrm{S}_{\text {depend }} \leftarrow\left\{\left(\mathrm{x}_{\mathrm{j}}, \mathrm{y}_{\mathrm{i}}\right) \mid \mathrm{p}\left(\mathrm{Y}=\mathrm{y}_{\mathrm{i}} \mid \mathrm{X}=\mathrm{x}_{\mathrm{j}}\right)-\mathrm{p}\left(\mathrm{Y}=\mathrm{y}_{\mathrm{i}}\right) \geq \lambda \wedge(1 \leq \mathrm{i} \leq \mathrm{m}) \wedge(1 \leq \mathrm{j} \leq \mathrm{n})\right.$

if $\left|\mathrm{S}_{\text {support }}\right|<\min \{\mathrm{n}, \mathrm{m}, \gamma\}$ then

generate item-based rules or quantative rules for $\mathrm{S}_{\text {support }}$;

else if $\left|S_{\text {conf }}\right|<\min \{n, m, \eta\}$ then

generate item-based rules or quantitave rules for $\mathrm{S}_{\text {conf }}$;

else if $\left|\mathrm{S}_{\text {depend }}\right|<\min \{\mathrm{n}, \mathrm{m}, \alpha\}$ then

generate item-based rules or quantitative rules for $\mathrm{S}_{\text {depend; }}$;

else let $\mathrm{RSET} \leftarrow$ the rule $\mathrm{X} \rightarrow \mathrm{Y}$ as an interest rule;

with conditional probability matrix of $\mathrm{Y}$ given $\mathrm{X}: \mathrm{M}_{\mathrm{Y} \mid \mathrm{X}}$; end do;

The statistical results of the working scarp requisition in the database denotes the conditional probability, and $19.5 \%$ denotes the happening probability of the coarse jaw breaking scrap by the workers' incorrect manipulation.

The scraps are divided into eleven sorts including coarse jaw breaking, fined jaw breaking, counterattack breaking, taper breaking, hammer breaking, roller breaking and so on, and the reasons of working scrap are divided into the workers' incorrect manipulation, damaged tools, improper manufacturing technology, inexact clamp, improper structure design and sufficient material performance (seen in Table 1).

The causal relations reflected in Table 1 are denoted as the conditional probability matrix, and various breaking factors are the state variable $\mathrm{X}$.

The matrix formed from Table 1 is

$\mathrm{A}_{11 \times 6}=\left(\begin{array}{cccccc}0.235 & 0.088 & 0.118 & 0.294 & 0.118 & 0.147 \\ 0.195 & 0.049 & 0.122 & 0.293 & 0.146 & 0.195 \\ 0.172 & 0.034 & 0.103 & 0.172 & 0.172 & 0.345 \\ 0.24 & 0.04 & 0.08 & 0.28 & 0.16 & 0.02 \\ 0.176 & 0.294 & 0.059 & 0.235 & 0.176 & 0.235 \\ 0.190 & 0.143 & 0.048 & 0.286 & 0.095 & 0.238 \\ 0.1 & 0.1 & 0.1 & 0.15 & 0.25 & 0.3 \\ 0.052 & 0.052 & 0.158 & 0.105 & 0.368 & 0.263 \\ 0.125 & 0.041 & 0.083 & 0.208 & 0.25 & 0.292 \\ 0.08 & 0.12 & 0.16 & 0.32 & 0.08 & 0.24 \\ 0.2 & 0.1 & 0.15 & 0.2 & 0.15 & 0.15\end{array}\right)$


In the statistical time, the production quantities of various products respectively are $40,3,9,101,1,9,61,2,23,3$ and 3 , and the production proportion of various products is $Z=(0.157,0.012,0.035,0.396,0.004,0.035,0.239,0.008,0.090$, $0.012,0.012)$, so according to $\mathrm{Z} \times \mathrm{A}_{11} \times{ }_{6}=\mathrm{Y}, \mathrm{Y}=(0.186575,0.068261,0.093545,0.239174,0.181641,0.159448)$, and $\mathrm{Y}$ is the weight value of various reasons combining the production proportion. From the information in $Y$, the improper structure design will impact the total production most, the technical improvement needs to be done by the technical department, and though the improper manufacturing technology has same impact on the scrap records with the improper structure design, but the improper manufacturing technology mainly impact the products with small production quantity, so its impacts are far less than the improper structure design. The system can deduct concrete rule expression aiming at concrete certain product, for example, the material return of drying breaking is mainly induced by the incorrect clamp. Therefore, the enterprise can adopt corresponding measures to modify the deficiencies according to the analysis results.

\section{System implementation}

The system adopts the B/S frame which is composed by server, networking computer and printer. The background database is the SQL Server 2000 relation database.

The user can click the tag page on the interface to operate. The materials are divided into the main machine and the structured part first, and then they are further sorted, which can help users to realize the print of various types of materials under the work order.

User can click "query of printing record", and inquire the total happening amount of scrap by inputting the checking conditions, and click the tag of "analyzing data", and input the time period, so the system can display the part sort and quantity of working scrap in this period, the working scrap happening amount of various products, the happening probability of various reasons, and the input reasoning rules.

\section{Conclusions}

Based on BOM data, the material requisition control system is designed and developed by adopting the B/S data interview mode, and it can simplify users' operations, realize the control of material requisition sort and quantity, implement data mining for the records of working scrap, analyze the main potential influencing factors, help the management layer to make relative decisions, and reduce the production cost. At present, the reason analysis is still deficient, and the system can only calculate the data according to the production amount proportion, and if the system can refer to the profits of various products to calculate the proportion of various products, the result will be more close to the benefits of the enterprise.

\section{References}

Lu, Juemin \& Zheng, Yu. (2007). Application of the Data Mining Technology Based on Matrix in Digital Library. Modern Information. No.12. P.92-98.

Lu, Jun, Zhong, Liangwei \& Ni, Jing. (2008). Application of Data Mining in Material Withdrawing and Returning Management System. Manufacturing Technology \& Machine Tool. No.7. P.138-141.

Shahbaz M., Srinivas, Harding, J.A. \& Turner, M. (2006). Product design and manufacturing process improvement using association rules. Proceedings of the Institution of Mechanical Engineers, Part B: Journal of Engineering Manufacture. No.220(2). P.243-254.

Siradeghyan Y., Zakarian A. \& Mohanty P. (2008). Entropy-based associative classification algorithm for mining manufacturing data. International Journal of Computer Integrated Manufacturing. No.21(7). P.825-838.

Zhang, Deqiang, Wang, Yansong, \& Geng, Aili. (2002). Development of the Material Information System. Journal of Liaoning Institute of Technology (Natural Science Edition). No.22(5). P.23-24.

Zhong, Zhi, Su, Yijuan \& Zhang, Shichao. (2002). Mining Causal Rules in Databases. Journal of Guangxi Teachers College (Natural Science Edition). No.19(4). P.77-80. 
Table 1. Data statistics

\begin{tabular}{|c|c|c|c|c|c|c|}
\hline Product type Reason & $\begin{array}{l}\text { Failure of } \\
\text { workers } \\
\text { to operate }\end{array}$ & $\begin{array}{l}\text { Damage } \\
\text { of tools }\end{array}$ & $\begin{array}{c}\text { Deficient } \\
\text { material } \\
\text { performance }\end{array}$ & $\begin{array}{l}\text { Improper } \\
\text { structure } \\
\text { design }\end{array}$ & $\begin{array}{l}\text { Inexact } \\
\text { clamp }\end{array}$ & $\begin{array}{l}\text { Improper } \\
\text { manufacturing } \\
\text { techniques }\end{array}$ \\
\hline $\begin{array}{l}\text { Coarse jaw } \\
\text { breaking }\end{array}$ & $8(23.5 \%)$ & $3(8.8 \%)$ & $4(11.8 \%)$ & $10(29.4 \%)$ & $4(11.8 \%)$ & $5(14.7 \%)$ \\
\hline $\begin{array}{l}\text { Fined jaw } \\
\text { breaking }\end{array}$ & $8(19.5 \%)$ & $2(4.9 \%)$ & $5(12.2 \%)$ & $12(29.3 \%)$ & $6(14.6 \%)$ & $8(19.5 \%)$ \\
\hline $\begin{array}{l}\text { Counterattack } \\
\text { breaking }\end{array}$ & $5(17.2 \%)$ & $1(3.4 \%)$ & $3(10.3 \%)$ & $5(17.2 \%)$ & $5(17.2 \%)$ & $10(34.5 \%)$ \\
\hline Taper breaking & $6(24 \%)$ & $1(4 \%)$ & $2(8 \%)$ & $7(28 \%)$ & $4(16 \%)$ & $5(2 \%)$ \\
\hline New taper & $3(17.6 \%)$ & $\begin{array}{l}2 \\
(29.4 \%)\end{array}$ & $1(5.9 \%)$ & $4(23.5 \%)$ & $3(17.6 \%)$ & $4(23.5 \%)$ \\
\hline $\begin{array}{l}\text { Roller } \\
\text { breaking }\end{array}$ & $4(19.0 \%)$ & $\begin{array}{l}3 \\
(14.3 \%)\end{array}$ & $1(4.8 \%)$ & $6(28.6 \%)$ & $2(9.5 \%)$ & $5(23.8 \%)$ \\
\hline $\begin{array}{l}\text { Hammer } \\
\text { breaking }\end{array}$ & $2(10 \%)$ & $2(10 \%)$ & $2(10 \%)$ & $3(15 \%)$ & $5(25 \%)$ & $6(30 \%)$ \\
\hline $\begin{array}{l}\text { Drying } \\
\text { breaking }\end{array}$ & $1(5.2 \%)$ & $1(5.2 \%)$ & $3(15.8 \%)$ & $2(10.5 \%)$ & $7(36.8 \%)$ & $5(26.3 \%)$ \\
\hline $\begin{array}{l}\text { Vibration } \\
\text { feeding } \\
\text { machine }\end{array}$ & $3(12.5)$ & $1(4.1 \%)$ & $2(8.3 \%)$ & $5(20.8 \%)$ & $6(25 \%)$ & $7(29.2 \%)$ \\
\hline vibration sieve & $2(8 \%)$ & $3(12 \%)$ & $4(16 \%)$ & $8(32 \%)$ & $2(8 \%)$ & $6(24 \%)$ \\
\hline \multirow[t]{2}{*}{$\begin{array}{l}\text { Plate feeding } \\
\text { machine }\end{array}$} & $4(20 \%)$ & $2(10 \%)$ & $3(15 \%)$ & $4(20 \%)$ & $3(15 \%)$ & $4(15 \%)$ \\
\hline & 46 & 21 & 30 & 66 & 47 & 65 \\
\hline
\end{tabular}




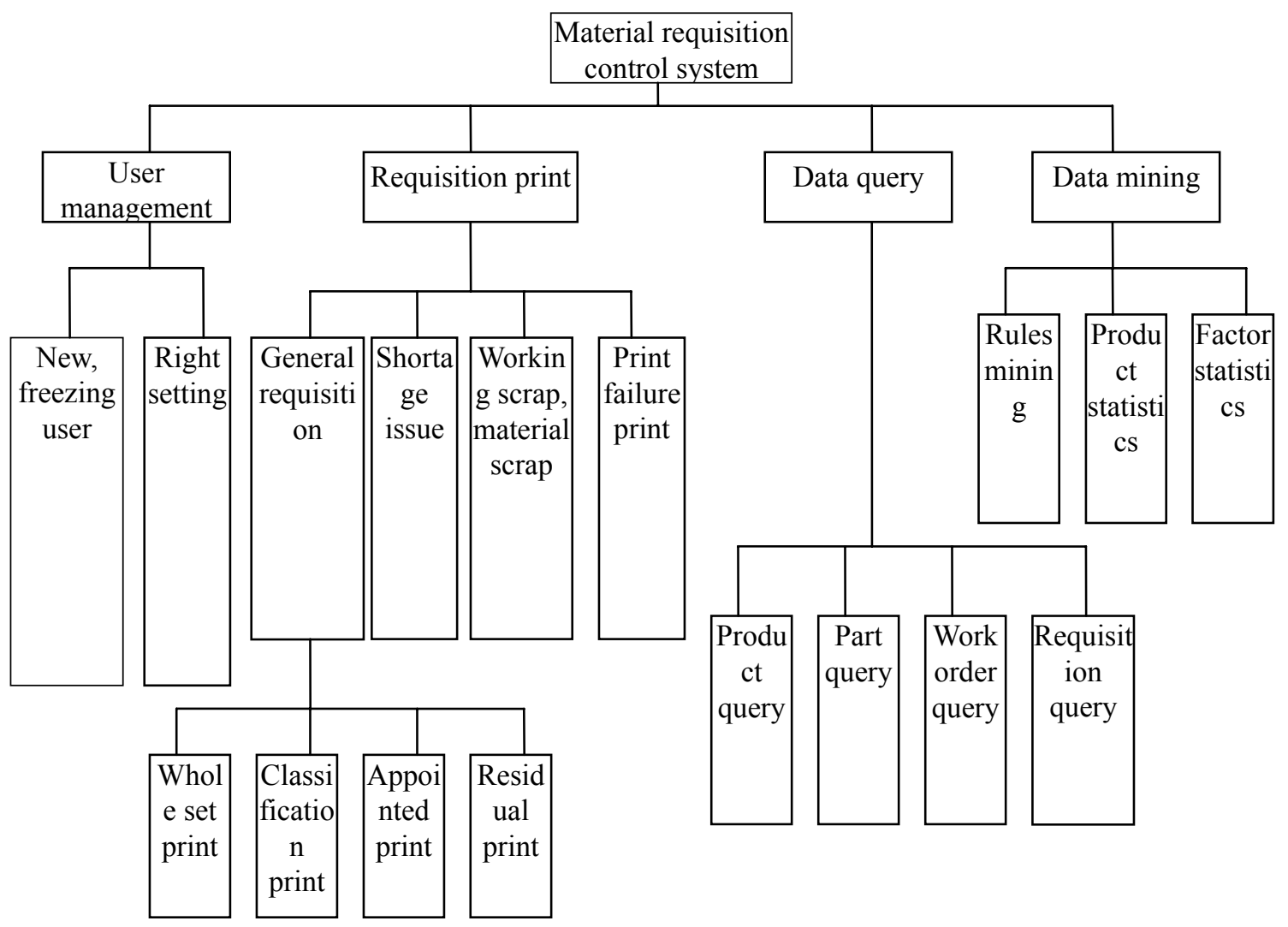

Figure 1. System Functional Diagram 